\title{
C. G. Jung's Thoughts on the Concepts of Leader and Leadership
}

\author{
John G. Corlett and Laura F. Chisholm
}

\begin{abstract}
A review of the written record suggests that C. G. Jung had relatively little to say about leadership. It also appears that the scattered comments he did make on the topic have garnered him little credit. Sensing, however, under-acknowledged value in Jung's offerings, the authors of the present study curate the various pieces of this material and comment on the relevance of Jung's thoughts to the field of leadership studies. The authors suggest caution in interpreting his ideas, given the differences between social norms prevailing in Jung's time and those current today, and recommend avenues for further application of Jung's ideas on leadership.
\end{abstract}

Keywords: archetype, cultural relativity, Dionysus, C. G. Jung, leader, leadership, leadership theory, personality, prestige, "so-called” leader, symbolic principles, “true” leader

\section{Introduction}

During his long career, C. G. Jung commented on leadership in a desultory manner. In what follows, the authors thematically organize Jung's previously uncollected statements on this topic, offer context and comment on the material where it seems useful to do so, and suggest two paths for further inquiry into leadership that could be seen as having fidelity to Jung's views on the matter.

Jung touched on the concepts of leaders and leadership-and a handful of closely related topics — on some dozen and a half occasions between 1932 and 1956, as recorded in his Collected Works, published letters, printed speeches, and transcribed media interviews. This study considers the following to be the principal sources of Jung's ideas about leaders and leadership: a 1932 lecture entitled “The development of personality," in which Jung detailed his ideas about the connection between leadership and individuation (1970b, paras. 284ff.); a 1933 lecture entitled "About psychology," in which Jung introduced the concepts of the "true" and the "so-called" leader (1970a, paras. 326ff.); a 1935 essay entitled "Phenomena resulting from the assimilation of the unconscious," in which Jung considered the development of prestige as a primary underpinning of leadership (1966b, paras. 237ff.); a 1936 newspaper article entitled "Wotan" in which Jung reflected on Adolf Hitler as a leader (1970a, paras. 391ff.); a collection of newspaper and radio interviews given by Jung during the 1930s and 1940s to a variety of media sources, in which Jung discussed the personalities of various world leaders of the time (found largely in McGuire \& Hull, 1977); a 1942 lecture entitled "The gifted child,” in which Jung focused on the relation between the leader and the collective unconscious (1970b, para. 248); and a 1945 newspaper article entitled “After the catastrophe” in which Jung returned to the theme of Hitler. (1970a, paras. 400ff.)1

Apart from the "Wotan” essay just noted, Jung's ideas about leadership have received scant attention in the significant body of work on leadership produced in recent decades by Jung-oriented scholars. Instead, these scholars have developed their arguments 
around one or more of Jung's more fully developed and better known ideas. Prominent scholarship in this field includes work relating leadership to the following: psychological types—Bridges (1992), Kroeger and Thueson (1992), Kroeger (1993), McCaulley (1993), Kets de Vries et al. (2010); Pearman (2014), Khan et al. (2016); archetypes-Neumann (1954), Mitroff (1989), Colman (1995), Pearson (1998), Conforti (1999), Mark and Pearson (2001), Corlett and Pearson (2003), Feldman (2004), Stein (2004), Abrahamson (2007), Colman and Ubalijoro (2012); the organizational unconscious-Corlett (1996), Stein (1996), Samuels (2000); myth-Gemmill and Oakley (1992), Bradley (2000); the Feminine-Beebe (2000), Meador (2000); individuation—Jironet and Stein (2012), Scott (2012); politics - Flowers (2000), Hinton (2000), Singer (2000); and dreams-Aizenstat (2012), Taylor (2012).

As was his wont in many arenas of his work, Jung neither consolidated nor systematized his thinking on leadership. Until now, the disparate elements have existed in a disorganized state, sprinkled across nearly three decades and various volumes. Moved to heighten the profile of this material by a sense of its potential value to leadership studies, the authors grappled with how best to bring some kind of order to it without reading into it more than Jung intended. A chronological arrangement of the material with an item-byitem commentary initially seemed plausible; but, in a dry-run of this approach, seemingly related fragments kept popping up erratically and disjointedly along the timeline. Utilizing conventional leadership models to frame Jung's thoughts also seemed to have promise, but none of the models assayed proved to be the equal of Jung's intellectual breadth. In the end, the authors approached the organization of the essay with intuition informed by interdisciplinary training: personal and professional grounding in social and humanistic psychologies; academic study in analytical psychology, history, economics, change theory, and diversity; and first-hand experience with leadership and management.

The authors' somewhat open-ended approach led to the creation of a kind of catalogue of Jung's fragmentary thoughts about leadership, organized around five themes: the concept of the "true" leader, the concept of the "so-called" leader, the connection between the achievement of personality and the leader, the link between leadership and the acquisition of prestige, and the influence of the great symbolic principles on the leader. The paper deals with these themes in the order noted, quoting or paraphrasing what Jung actually said or wrote on the subject at hand and providing contextual material from Jung's corpus and interpretive comments where these seem warranted. Interpretation turned out to play a fairly challenging role in dealing with the media material, given the tendentious nature of some of the questions Jung was asked to answer and the notoriety of the public figures he discussed.

The paper concludes with a broader discussion of the implications and import of Jung's thinking and points to opportunities for additional study informed by Jung's writings. It is offered with the hope of stimulating dialogue on and inquiry into Jung and leadership at a time when Jung's arguably valuable reflections are uniquely germane to current events. The authors acknowledge their own intrinsic biases and privileged positions within an inherently racist and sexist society. Without seeking to excuse the problematic aspects of Jung's writings as it relates to these issues, they propose that his thoughts on leadership, while situated within a troubling cultural context, can provide valuable touchstones for future scholarly work. 


\section{Jung's “True” Leader}

In a February 1933 lecture entitled “About psychology,” Jung (1970a, para. 326f.) stated:

The true leaders of mankind are always those who are capable of selfreflection, and who relieve the dead weight of the masses at least of their own weight, consciously holding aloof from the blind momentum of the mass in movement. But who can resist this all-engulfing force of attraction, when each man clings to the next and each drags the other with him? Only one who is firmly rooted not only in the outside world but also in the world within.

Jung's statement seems to point to a "true" leader who, above all, is introspective and who learns through inner work the importance of refraining from projection and of creating and maintaining a clear boundary between the Self and the collective psyche. Self-reflection leads the "true" leader down the path of self-development, a veritable leitmotif, of course, in Jung's corpus. Jung returned to the link between the leader and self-development - that is, individuation - in an interview broadcast on Radio Berlin in June, 1933. In the interview, he said: "Only the self-development of the individual, which I consider to be the supreme goal of all psychological endeavor, can produce consciously responsible spokesmen and leaders of the collective movement” (McGuire \& Hull, 1977, p. 64).

As for refraining from projection, Jung's use of the phrase "relieving the dead masses at least of their own weight" in the 1933 lecture can be understood at least in part as a metaphorical description of leaders who recognize and withdraw the projections of their shadow contents. By adhering to this discipline, "true" leaders can minimize the loss of personal integrity that can result from "foisting their own mistakes and merits onto others,” Jung's tongue-in-cheek allusion to projection (Jung, 1960, para. 584).

Eschewing projection also allows the "true" leader to avoid creating what Jung labeled unconscious, or "imaginary," relationships (1960, para. 507) with the led, relationships based on images that are frequently more reflective of the projector's complexes than of the object itself (1971, para. 812). Instead, by virtue of consciousness and emotional maturity, the "true" leader is able to foster what Jung termed "psychological relationships" (1970b, para. 325f.) with the led, relationships built on the mutual withdrawal of at least some projections and "mutual appreciation, understanding, and adaptation on the basis of each other's reality without either person losing his or her own individuality” (Mattoon, 1981, p. 213).

Jung discussed how important it is that the leader create and maintain a clear boundary between the Self and the collective psyche in a 1935 essay entitled "Phenomena resulting from the assimilation of the unconscious." He imagined how in a prehistoric community a quasi-historical figure he termed the "outstanding individual" became the first person to make the enormous psychological leap from languishing in identity with the unconscious collective psyche to seeing the first glimmerings of consciousness. This leap put this person on the road to self-realization and garnered them both deep respect in the community and a position of inchoate leadership (1966b, pars. 237-240).

\section{Putting a Face on the "True" Leader}

It appears that Jung did not write in detail about any historical "true" leader. That said, it seems that, during a 1936 visit to the United States, Jung may have glimpsed just a bit of 
the "true" leader in U.S. President Franklin D. Roosevelt. Having observed Roosevelt at close hand on several occasions, Jung told a reporter for the New York Times: "I am convinced that here is a strong man, a man who is really great. Perhaps that's why many people do not like him” (McGuire \& Hull, 1977, p. 88). Just two weeks later in an interview published in the Observer, Jung continued his praise of Roosevelt: "Make no mistake, he is a force - a man of superior and impenetrable mind.” But then he added that Roosevelt "has the most amazing power complex, the Mussolini substance, the stuff of a dictator absolutely” (pp. 92f.).

In its real-world messiness, the on-the-one-hand-on-the-other-hand treatment of Roosevelt may shed light on how Jung might have meant the reader to understand his somewhat abstruse presentation of the "true" leader quoted above. Taken as a commentary on his own definition, Jung's juxtaposition of Roosevelt's greatness and fallibility suggests that the reader probably needs to understand the "true" leader to be an unreachable ideal. That said, Jung reminded us that "unattainability is no argument against the ideal, for ideals are only signposts, never the goal” (1970b, para. 291). So, in his greatness, Roosevelt exemplifies the ideal of the "true" leader, while in his darker qualities he personifies the flawed human, who, in striving to be a leader, inevitably misses the mark at times along the way. Jung described Roosevelt as a stereotypically masculine leader who wields power and strength and is also flawed to the point of dangerous dictatorial proclivity. A contemporary reader might want to consider how integrating feminine/anima aspects of Self within the "true leader" ideal would form a more balanced leader. Although Jung himself did not make such a connection in reference to leadership, his description of the hermaphroditic rebis in his 1940 essay Psychology of the child archetype (1969b, para. 292) implied that a non-binary leader who expresses a mature integration of traditionally masculine and feminine aspects of Self could become a "subduer of conflicts and a bringer of healing” (para. 293) to social groups, organizations, and nations. The ability to integrate conscious and unconscious aspects of mind is reflected in 21st century Western culture's growing appreciation for both gender fluidity and the Indigenous Two-Spirit identity described by Lang (1997).

A humanized version of the "true" leader-accomplished, visionary, humane, and replete with human foibles-is probably what most of us mean when we use the word leader to describe someone. This is the exceptional person who possesses deep insight into the human condition, an unassuming character, a superior intellect, well-tuned people skills, and at least some understanding of their personal shadow. These characteristics probably bring the word leader to mind when we think of the great figures from history or those everyday managers and executives in our work lives for whom we would do almost anything.

Jung used the term "true leader" two additional times after introducing it in the February 1933 lecture noted at the beginning of this section. During an interview on Radio Berlin in June of that year, Jung said: "The true leader is always one who has the courage to be himself, and can look not only others in the eye but above all himself” (McGuire \& Hull, 1977, p. 64). In a 1938 interview with H. R. Knickerbocker, Jung said: "The true leader is always led" (p. 119; emphasis in the original). These quotations are mentioned here rather than at the beginning of this section, as each is embedded in a longer statement that includes a reference to Adolf Hitler and by doing so could raise questions about how it stacks up against the meaning of "true leader" as discussed above. 
Looking at the entire statement in which the June 1933 quotation is embedded, the authors conclude that the reference there to Hitler, although admittedly ambiguous, could be seen as indirect support for Jung's central point about the importance of self-knowledge on the part of the leader. Leading up to the quotation, Jung noted a then-recent statement by Hitler about the leader needing to have the courage to go his own way. Jung then went on to ask (arguably about Hitler) “But if he doesn't know himself, how is he to lead others?” (p. 64).

The 1938 quotation seems to be more problematic. The larger statement of which it is a part describes Hitler as someone with virtually no filter between his consciousness and his unconscious, someone, moreover, who acts with little or no reflection on what he hears from within (p. 119). Constituting the last sentence of the statement, the quotation in question seems pretty clearly, however, to label Hitler a "true leader," i.e., one described earlier in this section as a person who maintains an appropriate boundary between their unconscious and their presence in the world. For the authors, this clash raises considerable uncertainty about what Jung was saying.

\section{Jung's “So-called” Leader}

In the same 1933 lecture in which Jung introduced the concept of the "true" leader, he first used the term "so-called" leader, asserting: "So-called leaders are the inevitable symptoms of a mass movement." In the same breath Jung implied that the "so-called” leader lacks both self awareness and any understanding of projection (1970a, para. 326).

In a 1936 newspaper article entitled "Wotan” Jung observed: "But what a so-called Führer does with a mass movement can plainly be seen if we turn our eyes to the north or south of our country” (para. 395).

In a 1957 book entitled The undiscovered self (present and future), Jung, reflecting on totalitarian rule, wrote: "Furthermore, in order to compensate for its chaotic formlessness, a mass always produces a 'Leader,' who infallibly becomes the victim of his own inflated ego-consciousness, as numerous examples in history show” (para. 500). Given the context, Jung was probably being ironic here, inviting the reader to understand by his use of the apostrophes and the upper case "L" that he actually meant "so-called" leader.

These three quotations as a whole seem to point to a "so-called" leader who is unaware of the subjective unconscious, who regularly projects shadow contents onto others, and who-caught up in the unconscious projections of the mass movement-is subject to the whims of the collective psyche. Jung illustrated these characteristics with remarks about Italian dictator Benito Mussolini, Soviet dictator Joseph Stalin, and German dictator Adolf Hitler.

Jung was struck by the degree to which Mussolini was unaware of his subjective psyche. Substantiating his March 1936 characterization of Mussolini as a "so-called" leader (1970a, para. 395), Jung went on later the same year to note that, Mussolini, betraying his "identity with the Caesar," had "produced once more all the stage scenery of the Imperium which will soon reach from Ethiopia to the pillars of Hercules as of old" (1980, paras. 1328, 1333). In other words, Mussolini had identified with his Caesar complex. Jung returned to the theme of Mussolini's struggle with identity in a 1938 newspaper interview, noting that Mussolini "feels that he coincides with the national need" (McGuire \& Hull, 1977, p. 129). 
Attributing this kind of grandiosity to Mussolini resonated with Jung's comments in the 1935 essay noted above about what he termed "psychic inflation" (1966b, para. 227). Developing the theme further, Jung wrote: "When, therefore, I identify myself with my office or title, I behave as though I myself were the whole complex of social factors of which that office consists" (para. 227). "L'etat c'est moi is the motto for such people” (para. 227).

Discussing Stalin, Jung seemed to imply that, had he been asked, he would likely have put Stalin on his list of "so-called" leaders. He labelled Stalin a "strongman" who is "devouring the brood," "destroying what Lenin built." He saw Stalin as a "brute," who reminded him of a "Siberian saber-toothed tiger" with a "smile like a cat which has been eating cream.” He saw "no difference between Stalin and Ivan the Terrible” (McGuire \& Hull, 1977, pp.115-117, 130).

As with his evaluations of Mussolini and Stalin, Jung's assessment of Hitler made a strong case for the validity of his 1936 characterization of the German dictator as a "socalled” leader (1970a, para. 395). Jung was struck both by Hitler's lack of self-knowledge and by the depths of his unconscious psychological entanglement in the Nazi mass movement.

Regarding Hitler's lack of self-knowledge, Jung observed on one occasion that Hitler suffered from a complete absence of insight into his own character (1970a, para. 418). In a 1939 interview, Jung offered several observations that underscored this point. He said: "Hitler is all mask" (McGuire \& Hull, 1977, p. 138). He noted: "It is certain that Hitler does not understand himself" (p. 138) and observed: "Hitler has no real personal psychology" (p. 136; emphasis in the original). He argued that Hitler's passion for Germany was rooted in a "tremendous mother complex" (pp. 128f.).

Bolstering the case for Hitler's ignorance about his subjective psyche, Jung observed that Hitler was "diagnosed clinically as an hysteric" (1970a, para. 419). Jung noted further: "A more accurate diagnosis of Hitler's condition would be pseudologia phantastica, that form of hysteria which is characterized by a peculiar talent for believing one’s own lies” (para. 419). Underscoring this point, Jung wrote elsewhere of Hitler: "In other words, he was a 'pathological liar'” (1980, para. 1384).

Jung believed that Hitler "represented the shadow, the inferior part of everybody's personality” (1970a, para. 454). On the power of Hitler's shadow over his behavior, Jung wrote:

Hitler's magic, for instance, consisted in his always saying what everybody was afraid to say out loud because it was considered too disreputable and inferior (resentment against the Jews). But his daemonism lay in the fact that...he himself obviously became the victim of the daemon which had taken total possession of him” (1975, vol. 2, p. 82).

Reflecting on Hitler's relation to the collective unconscious, Jung said of Hitler: "He is the loudspeaker which magnifies the inaudible whispers of the German soul until they can be heard by the German's unconscious ear” (McGuire \& Hull, p. 118). Jung observed further that the German leader's "unconscious has exceptional access to his consciousness... and he allows himself to be moved by it" (p. 119). Jung suggested that Hitler is "like a man who listens intently to a stream of suggestions in a whispered voice from a mysterious source and then acts upon them" (p. 119; emphasis in the original). Finally, Jung observed 
that "Hitler has sacrificed his individuality, or else does not possess one in any real sense, to this almost complete subordination to collective unconscious forces” (p. 136).

Jung's concept of the "so-called" leader-much like his description of the term "true" leader-may seem at first glance to have an absolute and unyielding quality about it. However, the pictures Jung painted of Mussolini and Hitler arguably move the reader out of the rarefied air of psychological theory and make the case that the term "so-called" embraces a range of very human behaviors. Jung's examples delineate a portion of this range, running from Mussolini's brutishness and dictatorial strutting to Hitler's totalitarian frenzies and downright evilness. But Mussolini would seem to represent only the middle of the range and Hitler the extreme negative. At the relatively benign end of the range are organizational and political figures who, while demonstrating a lack of self-awareness no better or worse than that of their peers, engage in activities that stand in the shadowy margins of societally accepted behavior. Such behavior by leaders is dealt with, for example, in scholarship on the following: alleged anti-competitiveness activities in the "Big Tech" world (Popiel, 2018), cheating on environmental controls in the automotive industry (Mujkic \& Klinger, 2019), and alleged private executive misconduct (Lin, 2020).

It is worth emphasizing that Jung not only coined the terms "so-called" leader and "true" leader in the very same 1933 lecture but also introduced the two terms in consecutive sentences. Although Jung did not-then or ever-discuss the relationship between these concepts, it seems highly unlikely that this pairing was accidental. In juxtaposing the two terms, Jung was perhaps hinting that the "so-called" and the "true" in some way define each other, that they represent competing psychological tendencies and potentials that become constellated in the psyches of all who throw their caps into the leadership arena.

\section{Personality and the Leader}

In a 1932 lecture entitled "The development of personality," Jung said of personality: "It is able to cope with the changing times, and has unknowingly and involuntarily become a leader" (1970b, para. 306; emphasis in the original). In the same lecture, Jung noted that the person moving consciously toward developing a personality, remaining true to the law of the archetypal Self, becomes "the hero, the leader, the savior" (paras. 307ff.).

The term personality, as Jung used it in this speech and throughout his corpus, means “a well-rounded psychic whole" (1970b, para. 286). He observed: “The achievement of personality means nothing less than the optimum development of the whole individual human being. A whole lifetime, in all its biological, social, and spiritual aspects, is needed" (para. 289). Elsewhere, Jung noted that achieving an individual personality is in essence the phenomenon of individuation (1971, para. 757), a process of self-realization that enlarges the scope of the psyche by bringing into consciousness all the various contents of the personal unconscious, including shadow material (1966b, 103n, and para. 218).

At their respective cores, both quotations above suggest that Jung saw a causal relationship between the development of personality and the emergence of the leader. The authors suggest that Jung was arguing that the character of a leader grows out of the profoundly difficult, lifelong work of learning about and embracing the complexities of the personal psyche, the same work that governs the evolution of his "true" leader.

In these statements, Jung was referencing what one might name more precisely the conscious personality of a person who has confronted and integrated into consciousness most of what Jung labeled the "inferior personality" (1967b, para. 267) or "shadow" 
(1969a, para. 292). Such a person might equate with the "true" leader. By contrast, it is precisely the "hidden, repressed, for the most part inferior and guilt-laden personality" (1968, para. 422) that the "so-called" leader has neither acknowledged nor integrated into consciousness. Thinking along these lines provides not only a more robust and complete understanding of personality but also a clearer sense of the profound differences between the "true" and the "so-called" leader.

\section{Prestige and the Leader}

In the 1935 essay already cited, Jung reflected on the obvious fact that throughout history many individuals have succeeded in acquiring prestige. He acknowledged the role played in this development by an individual's "will to power." But he was quick to note that "the building up of prestige is always a product of collective compromise: not only must there be one who wants prestige, there must also be a public seeking somebody on whom to confer prestige." Pursuing this theme further, Jung observed that individuals may secure offices and titles for themselves by dint of significant personal effort but that the dignity of these positions "rests solely on collective approval” (1966b, paras. 227, 237f.).

In this reflection Jung referred to one of the persons seeking prestige as a "chief" and to those who accord him prestige as "his followers" (paras. 237, 238). With Webster's definition of prestige at hand, namely a "commanding position in men's minds" (1965, p. 674), it seems to the authors that in this passage Jung was-without using either the word leader or the word leadership-suggesting that leadership is rooted in a kind of mutuality.

A relational basis for leadership implies that the leader and the led engage in a twoway authorizing process similar to that which underpins other interdependent social roles (e.g., teacher, physician, mentor, pastor). The person who would lead has what Jung called a vocation, "an irrational factor that destines a man to emancipate himself from the herd and from its well-worn paths" (1970b, paras. 300-303). Though yearning to answer the unconscious call to leadership, such a person must in some manner find in others a validation of the call. The led must "sign the leader's license to operate” (G. L. Peabody, personal communication, 1987) before the leader/leadership nexus can come into being. Through this dynamic those who become followers legitimize, or at least acquiesce to, the would-be leader's desire to lead. Seen in this light, leadership is a functional relationship requiring both the psycho-social interpenetration of leader and led and the engagement of both in the leadership enterprise.

In the scenario from which Jung derived these comments about prestige, the one seeking prestige is evidently conscious to some significant degree; that is, moving on a path toward becoming a personality. By contrast, the persons bestowing the prestige seem to be essentially unconscious, willing to honor and elevate the "magically effective figure" (1966b, para. 237). This is but one possible authorizing dynamic along a spectrum of scenarios, each with a different mix of leader unconsciousness/consciousness and follower unconsciousness/consciousness. It is important to consider the implications of leadership prestige bestowed via unconscious authorization. This dynamic helps to explain the strong and enduring appeal (to some, at least) of leaders who are blind to their own shadows; given Jung's definitions, those who share shadow material with a leader would view these as "true"/conscious leaders, while those who are not held in thrall by the same complexes would perceive them as obviously exposed "so-called"/unconscious leaders. The authors propose that reasoning along this line implies that unconscious authorizing dynamics 
contribute to the deep and powerful political divide revealed so strongly in the last three U.S. presidential elections. It also follows that unconscious bestowal of prestige and power, especially among folk who do not consciously espouse racist ideology, is worthy of consideration as an important dynamic in the perpetuation of systemic bias and White supremacy. The authors invite further scholarly dialogue on these topics, especially from those with lived experience of racism and other forms of systematic oppression.

In the best of circumstances, the prestige dynamic would seem to pull the leaderfollower relationship out of the thrall of participation mystique and put it on a footing of mutual consciousness. The best case-and one that would seem to define the challenge of leadership in our own time-would pair a "true" leader with conscious followers. To this point, Neumann suggests that as human history unfolded, evolution came to be "characterized by a progressive democratization, in which a vast number of individual consciousnesses” work productively at the common human task” (1954, p. 434).

The worst case would link a "so-called" leader to an unconscious rabble. Suggesting support for this point is Jung's statement about Hitler in a 1946 BBC broadcast:

and thus a mob is formed. Its leader will soon be found in the individual who has the least resistance, the least sense of responsibility and, because of his inferiority, the greatest will to power. He will let loose everything that is ready to burst forth, and the mob will follow with the irresistible force of an avalanche. (1970a, para. 449)

It follows that the power of this dynamic correlates with the power of the complexes being activated and with the degree of unconsciousness of the material that comprises the complexes shared between leaders and the led.

\section{The Leader and the Great Symbolical Principles}

In a 1942 lecture entitled "The gifted child,” Jung said:

Human leadership being fallible, the leader himself has always been, and always will be, subject to the great symbolical principles, even as the individual cannot give his life point and meaning unless be puts his ego at the service of a spiritual authority superordinate to man. The need to do this arises from the fact that the ego never constitutes the whole of a man, but only the conscious part. The unconscious part, of unlimited extent, alone can complete him and make him a real totality. (1970b, para. 248)

It would seem that Jung was arguing here that the person called to be a leader cannot become a vital and creative practitioner of leadership without honoring and opening up to the power of the collective unconscious, notably the "great symbolical principles." Jung apparently used this term just in this instance, but he uses similar language in several other places in his corpus, in each case making the connection between something very much akin to his symbolical principles on the one hand and the archetypes on the other. Four examples of this follow. First, Jung recounted the connection made by Paracelsus between "eternal principles" and the "archetypal nature of consciousness" (1967a, para. 208). Second, in the same volume Jung wrote: "The empiricist tries, more or less successfully, to forge his archetypal explanatory principles....The Hermetic philosopher regarded these psychic premises, the archetypes, as inalienable components of the empirical worldpicture” (para. 378). Third, Jung used the term "archetypal principles” to describe the 
"Great Mother" and the "Father of All” (Jung et al., 1964, pp. 94f.). Fourth, Jung's musings about what he labelled the "principles" of "love" and "forethinking" (Jung, 2009, pp. 2524) suggest to the authors that in Jung's mind these elements were closely related to symbolical or archetypal principles.

From these examples the authors conclude that Jung may have intended the reader to see a close kinship between symbolical principles and the archetypes. And, whereas Jung had no more to say about the symbolical principles and leadership, he did connect two archetypes, the Hero and the Savior, to the concept of leader (1970b, para. 323). In the same vein, he linked the phrase "ruler of men and spirits" to the archetype of the manapersonality, and he implied that the archetype-derived symbol of the Great Mother (1969b, para.148) connotes the exercise of power and influence (1966b, paras. 377, 379, 389).

Beyond Jung's own musings, it would seem that any number of archetypes could plausibly be seen to influence the behavior of any given leader. Other candidates might be any of the twelve archetypes-among them the Lover, the Sage, the Magician, and the Creator - that Corlett and Pearson discussed in their reflections on organizational wholeness (2003). The list could also include many of the leading Greek gods and goddesses - each of whom symbolizes an archetypal pattern (Jung, 1969b). Zeus, Athena, Apollo, Dionysus and Hestia come readily to mind.

While Jung did not venture in his writing about leaders beyond representatives of the Western dominant-culture pantheon, other cultural traditions could richly inform inquiry and expostulation regarding archetypal "flavors" of leadership. Worth noting in this context are the three archetypally energized constructs posited by Samuels: the "erotic leader," the "trickster-as-leader," and "sibling leadership" (2000, pp. 39ff.). Also relevant are the relational models of leadership discussed by Stivers (2002), as well as the attributes of depth-inspired leaders that Hillman (1995) described, which "free the idea of leadership from images of the biggest, the bravest and the brawniest" (para. 1) and instead draw their influence from intuition, action balanced with reflection, an ability to be "tuned to the hidden” (para. 13), and affirmation of "the psyche's need to idealize, to imagine the far-off and the wonderful and let itself be captivated by vision” (para. 16).

Assuming a kind of synonymy between the great symbolical principles and the archetypes, it would hold that if, as Jung wrote, all archetypes have both positive and negative valences (1970a, para. 461), then so would the great symbolical principles. For a leader, this would make the embrace of these principles a weighty matter indeed. Jung made no mention in the statement that begins this section of the paper about how "true" and "so-called" leaders might be similar or different in their awareness and appreciation of the influence of the symbolical principles on their behavior. The reader might, however, infer from points made previously that the "true" leader would stand in awe before these primal elements of the collective unconscious. Having developed firsthand knowledge of the hallmarks of daemonic possession, such a leader could carefully guard against falling unknowingly under the power of either their constructive or destructive energies. By contrast, the "so-called" leader would witlessly and unconsciously fall under the sway of the collective unconscious in all of its manifestations, unleashing the scourges of psychic inflation and identity on friend and foe alike.

In ways that bring to mind the influence of the great symbolical principles, emotionally and psychologically charged philosophical ideas also can have powerful positive and negative effects on the cultures and leaders over which they hold sway. As 
with the symbolical principles, such "big" ideas are typically found in human experience paired with their opposites. The positive connotations can all too easily become the "received wisdom" in the collective mind of a dominant coalition. At the same time, the negative implications can easily slip into that coalition's behavioral shadow, alienating or disadvantaging individuals who differ from the majority by virtue of race, gender, sexual orientation, or ability.

A good example of this dynamic might be "freedom," as currently understood and practiced in U.S. society. It would seem that the dominant-mostly male and Whitecoalition assumes that the fruits of freedom, among them liberty and justice, are available to all. They are, however, arguably denied to many who are Black, Brown, female, or divergent from the dominant coalition's standard of "normal" in other ways. Liberty and justice for all lie in the shadow of freedom when freedom is interpreted by the powerful as doing what I want, or what we want, while consciously or unconsciously depriving others of their freedoms.

Faced with the shadow of freedom, "true" leaders would check both their personal shadows and the collective shadow for adverse impacts on any and all and seek to ameliorate untoward consequences. At the organizational level, such action could involve analyzing work processes to insure sure that there are no factors at play that prevent any individual from being as fully engaged in the work as they choose. Application of an "equity lens" framework - a consciously applied tool that guides structured reflection upon potentially unexplored implications prior to allocation of resources-is another example. ${ }^{2}$ At the national level "true" leadership could look like the establishment of truth and reconciliation efforts. Ignorant of the shadow of freedom, "so-called" leaders would, by contrast, blindly assume that the fruits of freedom are enjoyed fully by all. At the organizational level, this inequity could yield work processes and a work culture that militate against women, people of color and "others" of many descriptions. At the national level, it could lead to fundamental disenfranchisement and the legitimization of systemic bias.

\section{Discussion}

In a narrow sense, what Jung has left us in his fragments amounts to a list-admittedly of the authors' construction — of some significant acquired leader traits. The list includes the following: a deep personal knowing about the interpenetration of the rational ego and the irrational Self; an abiding respect for the influence of projection and participation mystique in the realm of leader-follower relationships; the clear knowledge that leader and led alike must in some sense conspire if the leadership dynamic is to come into existence; and a profound sense of wonder about and respect for the power of the objective psyche, not only over human happiness and global sustainability but also over misery and destructiveness. The authors would argue that every item on the list has prima facie validity and import, if only because each one stems from the breadth and profundity of Jung's life-long study of the human condition.

A wider view of the discrete elements of Jung's thinking traced in this essay demonstrates that each element is clearly grounded in Jung's concept of the psyche. Jung's concepts of the "true" and the "so-called" leader both focus on the intrapersonal aspect of the psyche. Taken together, they make the case for the centrality of individuation, or developing a personality, on the part of anyone aspiring to be the kind of leader suggested 
by Jung's description of the "true" leader. The inferred connection between prestige and leadership focuses on the interpersonal aspect of the psyche and argues that leadership at its best has an essentially relational quality. Jung's reflection on the influence of the great symbolic principles (archetypes) on the leader focuses on the role the transpersonal aspect of the psyche plays in energizing the leader/leadership nexus. Arguably, this deep-lying congruence among the fragments - suggesting the influence of a kind of implicate order of Jung's own creation-adds to the gravitas of each piece.

Further underscoring the substantive import and scholarly relevance of Jung's leader/leadership fragments, some of the particulars of Jung's thinking can be seen-in the useful work of both Kahn et al. (2016) and Amanchukwu et al. (2015) — to intersect with tenets of one or more conventional leadership theories. Jung's ideas about the development of personality seem to relate to the notions in traits-based and skills-based theories about the importance of learning and knowledge development on the part of the would-be leader. Ideas ascribed above to Jung about the reciprocal, relational nature of leadership seem to correspond to the thinking in contingency and transactional theories about the roles played by both leader and led in the development of leadership in given situations. Jung's ideas about the apparent role of symbolic principles and archetypes in the inspiriting of leadership seem to share ground with the concepts in transformational leadership theory pointing to how the best leaders call followers to the kind of higher and more universal needs, goals, and purposes that Abraham Maslow placed at the apex of his hierarchy of innate needs (1943).

Jung does not indicate clearly to which arenas or levels of socio-political activity his various comments on the leader/leadership nexus apply. This lack of clarity may simply be an artifact of Jung's not having systematized his thoughts on the subject. The reader cannot know for certain if Jung saw a distinction in principle between the ways leadership is practiced at the international, national, communal, and organizational levels. But there is evidence for making a reasonable guess as to what he might have said.

The data to support this conjecture may lie in the context of Jung's various remarks. The backdrops of his abstract comments about leaders and leadership run a broad gamut from worries about the stirring of the political mob, to a critique of the educational system, to an analysis of early clan politics, to somewhat jaundiced views about business and bureaucratic affairs, to idealistic speculations about human striving writ large. As for Jung's reflections on actual leaders, the context was the tumultuous events and chaotic politics of his day. Jung was prescient enough to identify the Germanic Wotan complex as an active underlay to the dramatic sociopolitical context of his early 20th century experience, yet it is likely that even he was under the influence of this zeitgeist. While it is, of course, challenging to untangle contemporary cultural complexes and projections without the benefit of hindsight, Jung's comments about leadership still provide a useful opportunity for reflection upon contemporary leaders. Archetypal musings aside, the bottom line here for Jungian leadership theorists is that Jung has provided several broad, fluid concepts about leadership and left the door wide open as to how and where they might be applied.

Finally, a word on "fragmentary," which—stated or implied-has been a constant in this essay. Have the authors "discovered" fragmentariness in Jung's treatment of leadership, or has a certain fragmentariness in their own views on the subject colored their analysis? Upon reflection, it would seem to be some of both, and the authors have come to 
suspect the unpredictable presence of Dionysus in both halves of the equation. Jung himself made a connection to Dionysus in his essay "Wotan" (1970a, paras. 391ff.), suggesting an archetypal backdrop to the social and political chaos that rocked Europe during the first half of the last century. At some level, this atmosphere must have influenced Jung's writing on leadership. A similarly disordered and unpredictable quality characterizes the political, economic and social disruptions of our own time and has undoubtedly played a role in shaping the authors' views of Jung's work.

\section{Looking Ahead}

Moving from discussion to speculation, the authors suggest that in his insistence on the fundamental relationship between becoming a leader and engaging in the individuation process, Jung may have unintentionally left a clue about how Jungian leadership theorists might move ahead with fundamental fidelity to his legacy. Jung once noted: "If the encounter with the shadow is the 'apprentice-piece' in the individual's development, then that with the anima is the 'master-piece'” (1969b, para. 61). If one were to take the shadow used in this way as standing for the personal psyche and the anima for the collective psyche, one would have a framework within which to explore the relationship between leadership and individuation through two different, but interrelated, Jungian lenses. In each case the focus would be on the ways in which the relative psychological maturity of the leader translates into either effective or ineffective leadership.

The "apprentice” approach would focus on the personal psyche of the leader. Work along this line would start, of course, with the relationship between ego and the shadow. It could also include analysis of the relationship between the ego and the persona, psychological types, and projection; and it might extend to a consideration of the complexes and to aspects of the Self. Jung's (1960) The structure and dynamics of the psyche might be a likely starting place for such research. The work of any number of Jung's followers could also offer valuable input; among many who could be named here, the researcher would do well to consult Quenk (1993) on psychological types, Edinger (1972) on the ego, Stevens (1982) on the Self, Jacobi (1959) on the complexes, Bly (1991) on the shadow, and Mattoon (1981) on projection and the persona.

The "master" or expert approach ${ }^{3}$ would center on the leader's relation to the collective psyche. Work along this line might start with the anima and animus, and would also examine the archetypal dynamics of the structures and processes mentioned in the preceding paragraph (Mattoon, p. 187). From there the exploration could move in any number of directions, including the synchronistic phenomenon of Dionysian leaders finding their way to power in times of chaos, manifesting common archetypal themes: verbal (and perhaps literal) dismemberment of those who threaten the leader's power and of existing structures and institutions; chaos and unpredictability; theatrics (especially the public tragedy of downfall); lack of a moral code beyond the self-serving; and the unconscious intoxication of power. Scholars could also analyze manifestations of the unconscious self-centeredness of Narcissus as reflected in leadership. Such inquiry could - and should - extend to expression of feminine, non-binary, and non-Western archetypes. For example, a potent opportunity for scholarship lies in the exploration of the archetypal energies of the Hindu dark mother goddess Kali in the leadership of contemporary liberation movements, such as Me Too and Black Lives Matter, that seek to dismantle oppressive White- and male-dominant power structures. 
The authors encourage scholarly inquiry and dialogue along the "apprentice" and "master"/expert lines, as well as constructive debate about whether it is possible to square the problematic nature of much of Jung's original considerations of leadership-including his use of language-against contemporary understanding of White oppression and structural racism. In these troubled and chaotic times, it behooves scholars not only to return to basics but also to question basic assumptions.

\section{Contributors}

John G. Corlett spent 25 years as a political analyst, as a manager, and finally as an internal change consultant for the federal government. He then taught for nearly 20 years at the University of Virginia. Mr. Corlett earned a $\mathrm{PhD}$ in organizational psychology from the Union Institute. He is the co-author of Mapping the Organizational Psyche. Email: jgcorlett@comcast.net

Laura F. Chisholm has worked in public health education, program implementation, and management for more than 18 years. She holds a $\mathrm{PhD}$ in depth psychology with emphasis in somatic studies from Pacifica Graduate Institute. Her 2018 dissertation, Seeing through to the organizational psyche: An archetypal analysis, explored the application of Jungian and archetypal psychology to the organizational development of a public agency. Email: laura.f.chisholm@gmail.com

\section{Notes}

${ }^{1}$ A chronological list of all the Jung material consulted in the research and writing of this essay includes the following: a 1932 lecture entitled "The development of personality" (Jung, 1970b, paras. 284ff.); a 1933 interview on Radio Berlin (McGuire and Hull, 1977, pp. 64f.); a 1933 lecture entitled “About psychology” (Jung, 1970a, paras. 326ff.); a 1935 essay entitled "Phenomena resulting from the assimilation of the unconscious" (1966b, paras. 237ff.); a 1936 lecture entitled "Psychology and national problems" (1980, paras. 1315, 1317); a 1936 newspaper article entitled “Wotan” (1970a, paras. 391ff.); a 1936 interview with the New York Times (McGuire and Hull, 1977, p. 88); a 1936 compendium of interviews with assorted journalists (pp. 91-93); a 1938 interview with H. R. Knickerbocker (p. 119); a 1939 interview with an English psychologist, published in The Psychologist (p. 137); a 1940 lecture at the Eranos meeting (Jung, 1969a, para. 222); a 1942 lecture entitled "The gifted child” (1970b, para. 248); a 1943 essay entitled “The Mana-personality” (1966b, paras. 374ff.); a 1945 interview published in Die Weltwoche (McGuire and Hull, 1977, p. 152); a 1945 article in the Neue Schweizer Rundschau entitled "After the catastrophe” (Jung, 1970, paras. 400ff.); a 1945 letter to Albert Oeri (1975, vol.1, p. 367); a 1946 BBC radio broadcast (1970a, paras. 444ff.); a 1952 letter to Horst Scharschuch (1975, vol. 2, pp. 81f.); and a 1956 book entitled The undiscovered self (1970) paras. 500, 535).

${ }^{2}$ An example of a tool used to promote equity and empowerment currently used in public administration is the Multnomah County, Oregon equity and empowerment lens. This package of structured questions, principles, and processes is intended to make planning, decision making, and resource allocation more racially equitable. These resources are available on the Web at https://multco.us/diversity-equity/equity-and-empowerment-lens (accessed November 11, 2020). 
3 The authors acknowledge the potentially offensive implications of the word master, which has been used in this instance to imply expertise rather than a power differential. We have chosen to echo Jung's original phrasing of the master/apprentice analogy in an attempt to accurately represent his original language, albeit in translation.

\section{References}

Abrahamson, N. R. (2007). The leadership archetype: a Jungian analysis of similarities between modern leadership theory and the Abrahamic myth in the JudaicChristian tradition. Journal of Business Ethics, 72, 115-129.

Aizenstat, S. (2012). Depth entrepreneurship: Creating an organization out of dream space. In C. S. Pearson (Ed.), The transforming leader (pp. 159-168). BerrettKoehler.

Amanchukwu, R. N., Stanley, G. J., \& Ololube, N. P. (2015). A review of leadership theories, principles, and styles, and their relevance to educational management. Management, 5(1), 6-14.

Bly, R. (1991). The long bag we drag behind us. In C. Zweig \& J. Abrams (Eds.), Meeting the shadow (pp. 6-12). Perigree Books.

Bradley, B. (2000). Reflections on myth, politics and leadership. In T. Singer (Ed.), The vision thing: Myth, politics and psyche in the world (pp. 23-27). Routledge.

Beebe, J. (2000). The wizard of Oz: A vision of development in the American political psyche. In T. Singer (Ed.), The vision thing: Myth, politics and psyche in the world (pp. 62-83). Routledge.

Bridges, W. (1992). The character of organizations. Consulting Psychologists Press.

Colman, A. D. (1995). Up from scapegoating. Chiron Publications.

Colman, A. D., \& Ubalijoro, E. (2012). Transmuting suffering: A leadership and advising perspective. In C. S. Pearson (Ed.), The transforming leader (pp. 130-139). Berrett-Koehler.

Conforti, M. (1999). Field, form, and fate. Spring Journal Books.

Corlett, J. G. (1996). The organization as psyche: A Jungian cartography of organizational dynamics. Harvest: Journal for Jungian studies, 45(2), 70-92.

Corlett, J. G., \& Pearson, C. S. (2003). Mapping the organizational psyche. Center for the Application of Psychological Type.

Edinger, E. F. (1972). Ego and archetype. Penguin Books.

Feldman, B. (2004). Towards a theory of organizational culture: Integrating the "other" from a post-Jungian perspective. In T. Singer \& S. Kimbles (Eds.), The cultural complex (pp. 251-260). Routledge.

Flowers, B. S. (2000). Practicing politics in the economic myth. In T. Singer (Ed.), The vision thing: Myth, politics and psyche in the world (pp. 207-212). Routledge.

Hillman, J. (1995). Kinds of power: A guide to its intelligent uses. Doubleday.

Hinton, A. L. (2000). Under the shade of Pol Pot's umbrella: Mandala, myth, and politics in Cambodian genocide. In T. Singer (Ed .), The vision thing: Myth, politics and psyche in the world (pp. 171-204). Routledge. 
Gemmill, G., \& Oakley, J. (1992). Leadership: an alienating social myth? Human relations, 45(2), 113-129.

Jacobi, J. 1959. Complex/archetype/symbol in the psychology of C. G. Jung. Bollingen Foundation.

Jironet, K. \& Stein, M. (2012). New approaches for leadership: A psychospiritual model for leadership development. In C. S. Pearson (Ed.), The transforming leader (pp. 181-190). Berrett-Koehler.

Jung, C. G. (1960). The structure and dynamics of the psyche (R. F. C. Hull, Trans.). In The collected works of C. G. Jung (Vol. 8). Pantheon Books.

Jung, C. G. (1966a). The practice of psychotherapy (R. F. C. Hull, Trans.). In The collected works of C. G. Jung (Vol. 16, $2^{\text {nd }}$ ed.). Princeton University Press. (Original work published in 1954.)

Jung, C. G. (1966b). Two essays on analytical psychology (R. F. C. Hull, Trans.). In The collected works of C. G. Jung (Vol. 7, $2^{\text {nd }}$ ed.). Princeton University Press. (Original work published in 1953.)

Jung, C. G. (1967a). Alchemical studies (R. F. C. Hull, Trans.). In The collected works of C. G. Jung (Vol. 13). Princeton University Press. (Original work published in 1967.)

Jung, C. G. (1967b). Symbols of transformation (R. F. C. Hull, Trans.). In The collected works of C. G. Jung (Vol.5, $2^{\text {nd }}$ ed.). Princeton University Press. (Original work published in 1956.)

Jung, C. G. (1968). Aion (R. F. C. Hull, Trans.). In The collected works of C. G. Jung (Vol. 9, Pt. 2, $2^{\text {nd }}$ ed.). Princeton University Press. (Original work published in 1959.)

Jung, C. G. (1969a). Psychology and religion: West and east (R. F. C. Hull, Trans.). In The collected works of C. G. Jung (Vol. 11, $2^{\text {nd }}$ ed.). Princeton University Press. (Original work published in 1958.)

Jung, C. G. (1969b). The archetypes and the collective unconscious (R. F. C. Hull, Trans.). In The collected works of C. G. Jung (Vol. 9, Pt. 1, $2^{\text {nd }}$ ed.). Princeton University Press. (Original work published in 1959.)

Jung, C. G. (1970a). Civilization in transition (R. F. C. Hull, Trans.). In The collected works of C. G. Jung (Vol. 10, $2^{\text {nd }}$ ed.). Princeton University Press. (Original work published in 1964.)

Jung, C. G. (1970b). The development of personality (R. F. C. Hull, Trans.). In The collected works of C. G. Jung (Vol. 17). Princeton University Press. (Original work published in 1954.)

Jung, C. G. (1971). Psychological types (R. F. C. Hull, Trans.). In The collected works of C. G. Jung (Vol. 6). Princeton University Press. (Original work published in 1971.)

Jung, C. G. (1975). Letters. 2 vols. (G. Adler \& A. Jaffe, Eds.). Princeton University Press. (Original work published on various dates.) 
Jung, C. G. (1980). The symbolic life (R. F. C. Hull, Trans.). In The collected works of C. G. Jung (Vol. 18). Princeton University Press. (Original work published on various dates.)

Jung, C. G. (2009). The red book. Norton \& Company.

Jung, C. G., von Franz, M.-L., Henderson, J. L., Jacobi, J., \& Jaffe, A. (1964). Man and his symbols. Doubleday.

Kahn, Z. A., Nawaz, A., Khan, I., \& Khan, D. I. (2016). Leadership theories and styles. Journal of resources development and management, 16(1), 1-8.

Kets de Vries, M. F. R., Vrignaud, P., Agrawal, A., \& Florent-Treacy, E. (2010). Development and application of the leadership archetype questionnaire. The international journal of human resource management (published on-line on 4 December, 2010), 2848-2863.

Kroeger, O. (1993). Leadership: A new definition. Presentation: Special topic symposium. The Association for Psychological Type.

Kroeger, O., \& Thuesen, J. (1992). Type talk at work. Delacorte Press.

Lang, S. (1997). Various kinds of two-spirit people: Gender variance and homosexuality in Native American communities. Two-spirit people: Native American gender identity, sexuality, and spirituality. University of Illinois Press.

Lin, T. C. W. (2020). Executive private misconduct. George Washington law revue, 88(2), (327-391.

Maslow, A. H. (1943). A theory of human motivation. Psychological review, 50(4), 370 96.

Mark, M. \& Pearson, C. S. (2001). The hero and the outlaw. McGraw-Hill.

Mattoon, M. A. (1981). Jungian psychology in perspective. The Free Press.

McCaulley, M. H. (1993). Leadership in a time of change: Challenges for the MBTI. Presentation: Special topic symposium. The Association for Psychological Type.

McGuire, W., \& Hull, R. F. C. (Eds.) (1977). C. G. Jung speaking. Princeton University Press.

Meador, B. M. (2000). The feminine and politics. In T. Singer (Ed.), The vision thing: Myth, politics and psyche in the world (pp. 50-61). Routledge.

Mitroff, I. I. (1989). Stakeholders of the organizational mind. Jossey-Bass Publishers.

Mujkic, E., \& Klinger, D. (2019). Dieselgate: How hubris and bad leadership caused the biggest scandal in automotive history. Public integrity, 21(4), 365-377.

Neumann, E. (1954). The origins and history of consciousness. Princeton University Press.

Pearman, P. P. (2014). Type and leadership: Leaning forward. Bulletin of psychological type, 37(1), 23-25.

Pearson, C. S. (1998). Thinking about business differently: Organizational systems and leadership archetypes. InnoVision Communications.

Pearson, C. S. (2003). Organizational and team culture indicator. CAPT. 
Popiel, P. (2018). The tech lobby: Tracing the contours of new media elite lobbying power. Communication, culture \& critique, 11(4), 566-585.

Quenk, N. L. (1993). Beside ourselves. Consulting Psychologists Press.

Samuels, A. (1998). Will the post-Jungians survive? In A. Casement, (Ed.), PostJungians today: Papers on contemporary analytical psychology (pp. 15-32). Routledge.

Samuels, A. (2000). The good-enough leader. In T. Singer, (Ed.), The vision thing: Myth, politics and psyche in the world (pp. 34-49). Routledge.

Scott, K. T. (2012). The new basics: Inner work for adaptive challenges. In C. S. Pearson (Ed.), The transforming leader (pp. 93-101). Berrett-Koehler.

Singer, T. (2000). Introduction: the vision thing. In T. Singer (Ed.), The vision thing: Myth, politics and psyche in the world (pp. 1-18). Routledge.

Stein, M. (1996). Practicing wholeness: Analytical psychology and Jungian thought. Continuum.

Stein, M. (2004). On the politics of individuation in the Americas. In T. Singer \& S. Kimbles, (Eds.), The cultural complex (pp. 262-273). Routledge.

Stevens, A. (1982). Archetypes: a natural history of the self. Quill.

Stivers, C. (2002). Gender images in public administration: Legitimacy and the administrative state (2nd ed.). Sage.

Taylor, J. (2012). It's all a dream: Depth approaches to understanding and withdrawing projection. In C. S. Pearson (Ed.), The transforming leader (pp. 191-200). Berrett-Koehler.

Webster's Seventh New Collegiate Dictionary (1965). G. \& C. Merriam. 